\title{
Transient Complete Heart Block after Percutaneous Transcatheter ASD Device Closure
}

\author{
Revanth Vulli ${ }^{1}$, Nagabhushan Doddakal ${ }^{1}$, VikasKadiyala ${ }^{2}$ \\ ${ }^{1}$ Senior Resident, ${ }^{2}$ Assistant Professor, \\ Department of Cardiology, Narayana Medical College, Nellore - 524003 \\ Corresponding Author: Vikas Kadiyala
}

\begin{abstract}
Transcatheter device closure of atrial septal defect (ASD) is associated with increased complications in small children in device size $\geq$ $19 \mathrm{~mm}$ or indexed size $\geq 0.18 \mathrm{~mm} / \mathrm{cm}$ and weight $\leq 15 \mathrm{~kg}$. Complete atrioventricular heart block (CHB) is reported as a rare complication of ASD device closure. We report the case of a 7year-old boy, 23kg weight, underwent device closure of ASD and subsequently developed CHB next day after the procedure which was completely resolved by day 3 with steroid treatment. Similar case reports were rarely reported in the literature.
\end{abstract}

Key words: atrial septal defect, complete heart block, device/height ratio

\section{INTRODUCTION}

Percutaneous transcatheter closure of ostium secundum ASD is being increasingly attempted in small children due to development in device technology and was reported to have increased frequency of major and minor complications in small children weighing less than $15 \mathrm{~kg}$ with event rate accounting to $5.5 \%$ and $9.4 \%$ respectively. ${ }^{[1]} \mathrm{ASD}$ device closure is less commonly associated with atrioventricular conduction blocks (AVB) than Ventricular Septal Defect device closure. The reported incidence of AVB varies from $<1 \%$ to $6.1 \%$ following ASD device closure. ${ }^{[1-4]}$

\section{CASE REPORT}

A 7-year-old boy, presented with history of recurrent lower respiratory tract infections since the age of 3months. He was $112 \mathrm{~cm}$ tall and weighed $23 \mathrm{~kg}$. Physical examination was suggestive of ASD. Baseline 12-lead electrocardiogram (EKG) showed normal sinus rhythm, RBBB with no conduction delays (Fig.1). On Transthoracic 2D echocardiography $22 \mathrm{~mm}$ ASD was found with adequate superior, posterior and inferior rims along with dilated right atrium and right ventricle. Pulmonary to systemic flow (Qp/Qs) was 3.5:1 with normal pulmonary arterial pressure. After confirming drainage of three pulmonary veins into left atrium, transcatheter device closure of ASD was carried out under general anesthesia with 26 mm Lifetech Cera Multi-fenestrated ASD occluder. EKG monitoring during the procedure was within normal limits. There is neither residual shunt nor impingement on atrioventricular valves was found on post procedure 2D echocardiography (Fig. 2). EKG monitoring on next day showed complete heart block (CHB) with a ventricular rate of 90 beats per minute (Fig.3). As the patient was asymptomatic and hemodynamically stable, oral prednisolone course at $1 \mathrm{mg} / \mathrm{kg} / \mathrm{day}$ and aspirin at a dose of $10 \mathrm{mg} / \mathrm{kg} /$ day to decrease the inflammation and edema around the AV node were started assuming the above cause as reason for conduction problems. On day 3 of steroid treatment, patient reverted to normal sinus rhythm with no conduction delays or blocks (Fig. 4). A 5-day course of steroids was administered in the hospital, before patient was discharged 
to home with a prescription of aspirin for 3months and a 5-day steroid taper. He remained asymptomatic with normal sinus rhythm with no recurrence of heart block at 6 months of follow up.

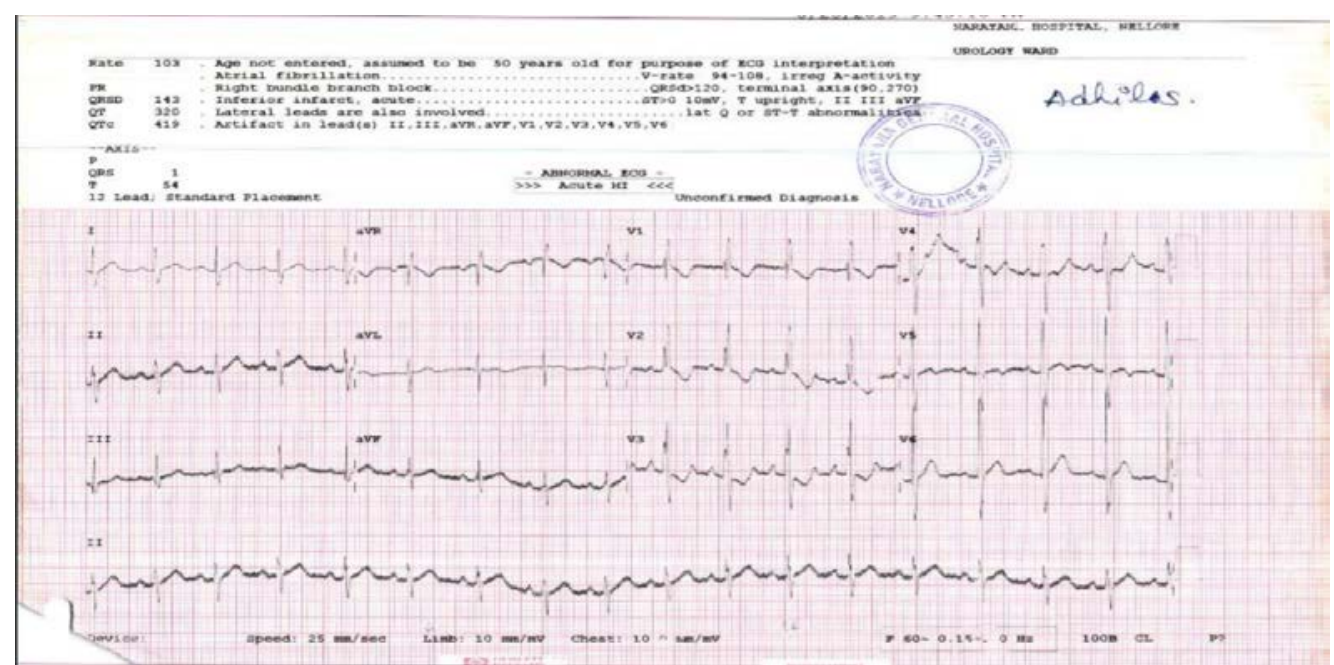

Fig. $1 \mathrm{EKG}$ at the time of presentation with sinus rhythm and RBBB

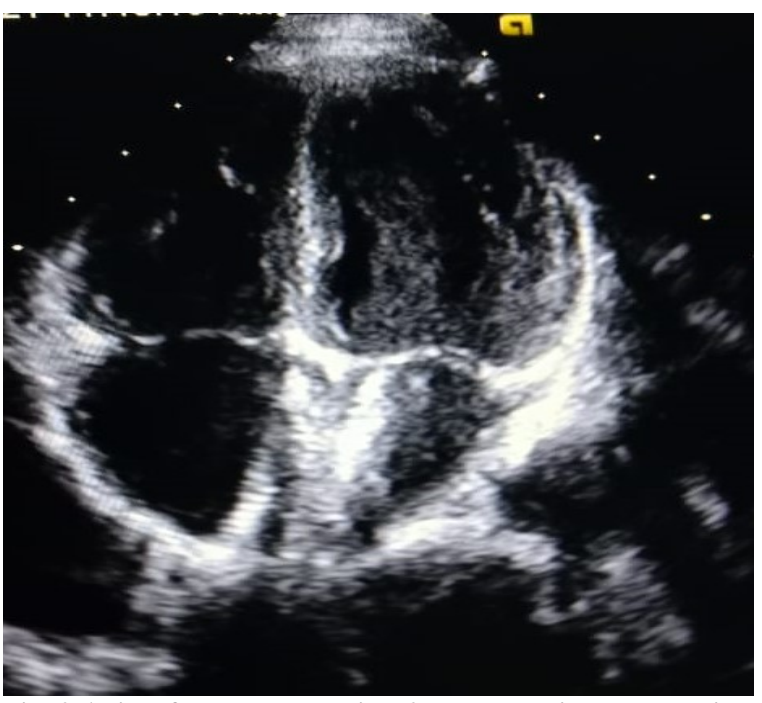

Fig. 2 Apical four chamber view 2D echocardiogram showing ASD device in Situ with no impingement on the atrioventricular valves

\section{DISCUSSION}

In ASD baseline conduction defects may occur due to proximity of defect to the AV node in the triangle of Koch and hemodynamic changes and chamber dilation that occur secondary to the defect. This anatomic location may predispose conduction disturbances on any septal repair procedure. This risk of arrhythmias ranges from 10 to $30 \%$ with open surgical repair and about $1-6 \%$ after percutaneous device closure. ${ }^{[5]}$ The onset may be as early during device deployment to as late as few days to weeks. Late progression of first degree
AVB to complete heart block four years after ASD device closure was described in one of the case reports. ${ }^{[6]}$ Most of the studies reported complications in children less than $15 \mathrm{~kg}$, but in our case the child is $23 \mathrm{~kg}$ and this is the first case of CHB we have encountered, which spontaneously reverted with steroid therapy.

One of the important risk factors for development of CHB is deficient posteroinferior rim. But in spite of adequate postero-inferior rim, our patient developed CHB. The inflammation and edema caused around the AV node by the atrial discs is partly considered as etiology of the conduction blocks after ASD device closure which is the basis for empirical steroid therapy in such cases, along with evidence from studies of ventricular septal defects on conduction blocks after device closure ${ }^{[7,8]}$ However there have been cases where steroids were not useful and hence the recommendations on this issue are not standardised. ${ }^{[9]}$ In our case the cause of CHB is assumed to be due to inflammatory edema and transient ischemia of the AV node secondary to mechanical irritation by ASD device, which responded with antiinflammatory therapy. Risk factors for development of AVB include hemodynamically significant defect with 
QP/QS ratio $>2.8$, larger defects ${ }^{[10]}$ with greater device/height ratio $\geq 0.18 \mathrm{~mm} / \mathrm{cm}$, larger devices, short distance between right atrial disk to tricuspid valve, deficient postero-inferior rim where in our case
QP/QS ratio was around 3.5 and device by height ratio $0.23 \mathrm{~mm} / \mathrm{cm}$ with adequate distance between right atrial disc to tricuspid valve with adequate posteroinferior rim.

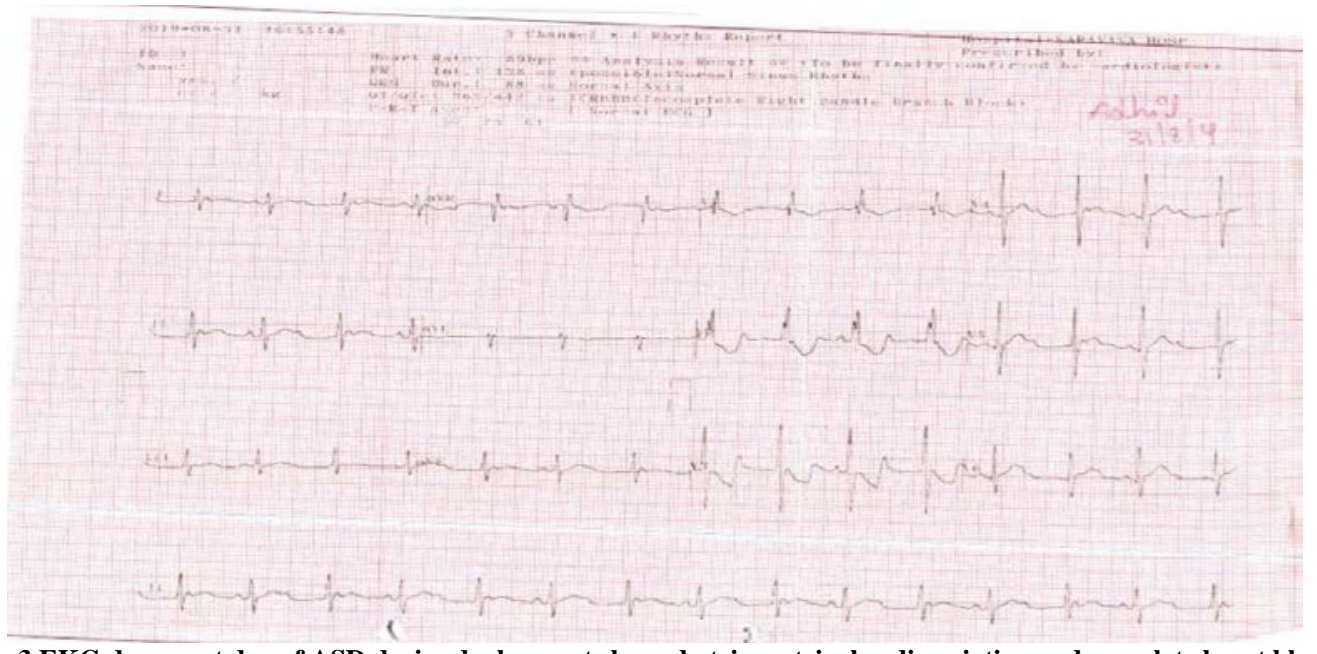

Fig. 3 EKG done next day of ASD device deployment showed atrioventricular dissociation and complete heart block.

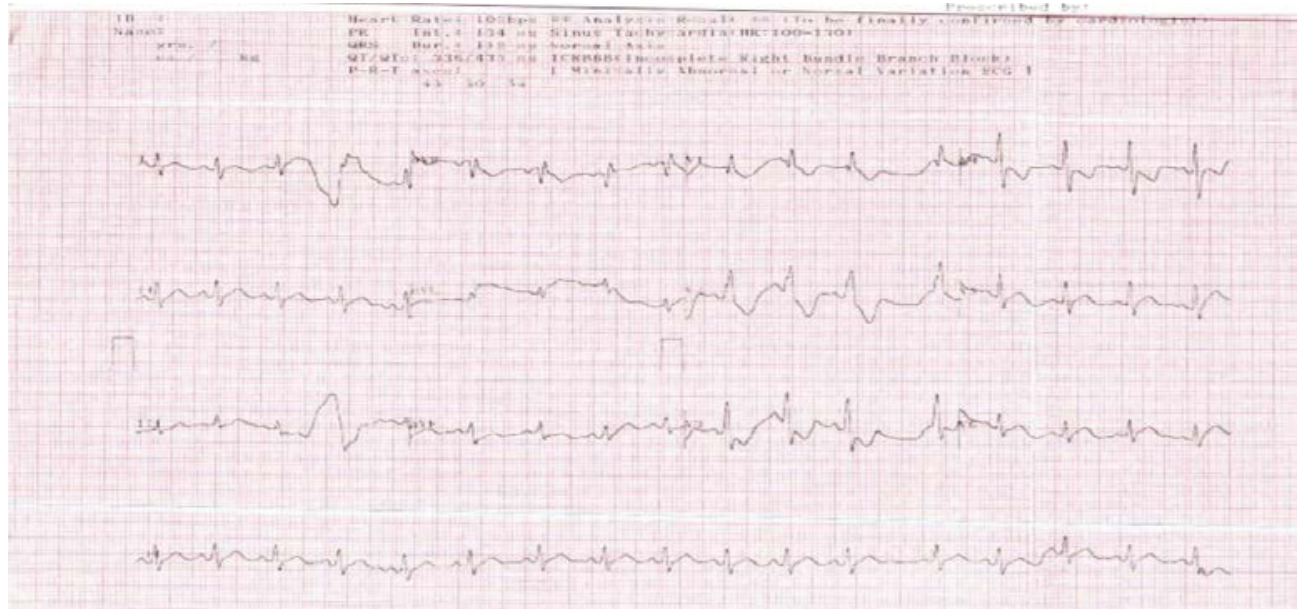

Fig. 4 EKG at third day showed normal sinus rhythm with resolution of complete heart block.

\section{CONCLUSION}

Most of the studies had reported complications in children less than 15kg, but in this case we encountered such complication with child weighing $23 \mathrm{~kg}$, with device height ratio of $0.23 \mathrm{~mm} / \mathrm{cm}$, device size of $26 \mathrm{~mm}$ and adequate posteroinferior margin signifying the cause of conduction defects mainly depends on device size and device height ratio, less dependent on weight of patient and steroid therapy playing a major role in CHB after device closure.

\section{Acknowledgement: None}

\section{Conflict of Interest: None}

\section{Source of Funding: None}

\section{REFERENCES}

1. Bartakian S, Fagan TE, Schaffer MS, Darst JR. Device closure of secundum atrial septal defects in children <15 kg: complication rates and indications for referral. JACC CardiovascInterv. 2012;5:1178-84.

2. Suda K, Raboisson MJ,Piette E, Dahdah NS, Miro J. Reversible atrioventricular block associated with closure of atrial septal defects using the Amplatzer device. J Am CollCardiol. 2004;43:1677-82. 
3. Rocchini A, Lock JE. Defect closure: Umbrella devices In: Lock JE, Keane JF, Perry SB, editors. Diagnostic and Interventional Catheterization in Congenital Heart Disease. 2nd ed. Norwell, MA: Kluwer Academic, 2000:179-98

4. Chan KC, Godman MJ, Walsh K, Wilson N, Redington A, Gibbs JL. Transcatheter closure of atrial septal defect and interatrial communications with a new self expanding nitinol double disc device (Amplatzer septal occluder): multicentre UK experience. Heart. 1999;82:300-6.

5. Bialkowski J, Karwot B, Szkutnik M, Banaszak P, Kusa J, Skalski J. Closure of atrial septal defects in children: surgery versus AmplatzerA $\hat{A}^{\circledR} \quad$ device implantation. Tex Heart Inst J. 2004;31: 220.

6. Nehgme R.A., Huddleston A.R., Cheatham J.P. Progression to late complete atrioventricular block following Amplatzer device closure of atrial septal defect in a child. PediatrCardiol. 2009;30:367-370.

7. Hill SL, Berul CI, Patel HT, Rhodes J, Supran SE, Cao QL. Early ECG abnormalities associated with transcatheter closure of atrial septal defects using the Amplatzer septal occluder. J Interv Card Electrophysiol. 2000;4:469-74.

8. Rohit MK, Puri K, Vadivelu R. Reversible complete atrioventricular block after percutaneous ASD device closure in a child $<15$ kg. Indian Heart J. 2014;66:366-369.

9. Yip WC, Zimmerman F, Hijazi ZM. Heart block and empirical therapy after transcatheter closure of perimembranous ventricular septal defect. Catheter CardiovascInterv. 2005;66:436-41.

10. Chessa M, Carminati M, Butera G, Bini RM, Drago M, Rosti L, et al. Early and late complications associated with transcatheter occlusion of secundum atrial septal defect. J Am CollCardiol. 2002 Mar 20;39(6):10615.

How to cite this article: Vulli R, Doddakal N, Kadiyala V. Transient complete heart block after percutaneous transcatheter ASD device closure. International Journal of Research and Review. 2021; 8(11): 113-116. DOI: https:// doi.org/10.52403/ijrr. 20211115 